\title{
Critical analysis of endomyocardial biopsies from patients suspected of having cardiomyopathy II: Comparison of histology and clinical/haemodynamic information
}

\author{
U BAANDRUP, * R A FLORIO, M REHAHN, P J RICHARDSON, \\ E G J OLSEN
}

From the Cardiothoracic Institute, University of London, and Department of Histopathology, National Heart Hospital, London

SUMMARY Endomyocardial biopsies showing histological evidence of "ordinary" hypertrophy or changes compatible with congestive cardiomyopathy (COCM) were obtained from 125 patients.

Statistical analysis compared histological/morphometric data with clinical/haemodynamic findings such as ejection fraction, left ventricular end-diastolic pressure, and length of history. Patients were grouped either according to the histological description or the clinical diagnosis. Comparison of the morphological description with the final clinical diagnosis was also undertaken. Follow-up of the patients was between two and 66 months.

The results of the statistical analyses showed no correlation between quantitative, morphological assessment and either clinical information, that is length of history and subsequent course, or the haemodynamic variables.

In 86 per cent of cases a rough agreement between the morphological description and the clinical diagnosis was obtained, but no specific pattern permitting a morphological diagnosis of COCM was established.

The findings suggest that pronounced topographic variation in biopsy material exists and that, therefore, the severity of COCM or its prognosis cannot be assessed from histological changes.

Since the introduction of the bioptome technique by Sakakibara and Konno ${ }^{2}$ this method of obtaining fresh endomyocardial tissue has been used with increasing frequency, particularly in the last decade. The analyses to which the samples have been subjected have been manifold and include diagnostically descriptive aspects, ${ }^{3-5}$ biochemical analyses, ${ }^{6-8}$ and immunological studies. ${ }^{9} 10$ Correlative studies comparing morphological features and clinical variables have been undertaken with differing results. ${ }^{11} 12$

The purpose of this investigation was to ascertain whether or not morphology could predict the functional state of the myocardium, as expressed by ejection fraction of the left ventricle, left

\footnotetext{
* Present address: Kandidatstipendiat, University Institute of Pathology, University of Aarhus, Municipal Hospital, 8000 Aarhus C, Denmark.

Received for publication 24 September 1980
}

ventricular end-diastolic pressure, and length of history, and the prognosis. The comparability of descriptive morphology and the final clinical diagnosis were also assessed.

\section{Subjects and methods}

Biopsies were obtained from 143 male and 58 female patients with an average age of 43.7 years (range 4 to 72 years) suspected of having some form of cardiomyopathy.

In order to compare histological/morphometric data with clinical/haemodynamic information, patients with either histological "ordinary" hypertrophy or with changes usually agreed to be compatible with congestive cardiomyopathy were selected. Endomyocardial biopsies were obtained by the small Konno-Sakakibara or the King's instrument. The tissue was frozen in melting "Freon" 487 
(BOC) precooled in liquid nitrogen or fixed in 3 per cent cacodylate buffered glutaraldehyde.

Frozen sections, $5 \mu \mathrm{m}$ thick, were cut on a Bright's cryostat with a chamber temperature of $-20^{\circ} \mathrm{C}$, and paraffin-embedded material fixed in glutaraldehyde were cut on a Jung's base sledge microtome.

In every instance haemotoxylin-eosin and elastic van Gieson stains were used.

Morphological assessment included structural changes in the myocardium, the endocardium, and the interstitium. Quantitative measurements of fibre diameter, volume fraction of collagen tissue, and interstitium were also undertaken.

Experience from a pilot study of endomyocardial biopsies from 150 patients formed the basis for the descriptive terms employed:

Hypertrophy: hypertrophy of myocardial fibres and nuclei, and no other significant changes.

Congestive cardiomyopathy (COCM): this cannot be conclusively diagnosed from histological examination as no single feature or features are pathognomonic. Biopsies showing either hypertrophy plus attenuation of muscle fibres, or hypertrophy plus smooth muscle cell hypertrophy (hyperplasia) of endocardium, or hypertrophy plus attenuation of muscle fibres plus smooth muscle cell hypertrophy of the endocardium were included, these features being compatible with such a diagnosis.

\section{CATHETERISATION, HAEMODYNAMIC MEASUREMENTS, AND FOLLOW-UP OF PATIENTS}

The Seldinger technique ${ }^{13}$ or cutdown had been used for right- or left-sided catheterisation. Left ventricular end-diastolic pressures and the findings on selective coronary angiography were obtained from the catheterisation reports but the former were ignored in patients with significant valve gradients. In none of the patients were there any anatomical or significant pathological abnormalities of the coronary arteries. ${ }^{14}$

Left ventricular angiography was performed in the right anterior oblique projection at $35^{\circ}$, and angiograms were used to calculate the ejection fraction by the area-length method of Sandler and Dodge. ${ }^{15 \star}$

The electrocardiogram was either normal or, more often, showed non-specific changes. ${ }^{14} 17$

Clinical and follow-up information was obtained from the case notes and from the responsible physicians. Though at the time of the biopsy cardiomyopathy was the provisional diagnosis in all patients, in some this was changed later, either because the biopsy was diagnostic of some other heart disease, or because hypertension developed, or because repeat coronary angiography showed coronary arterial disease, and so forth.

Functional grouping (New York Heart Association) was not undertaken by all departments involved in the study.

\section{STATISTICAL METHODS}

The tests carried out included $\chi^{2}$ test, $t$ test, one-way analysis of variance, two-way analysis of variance, correlation analysis, and multivariate techniques (multilinear regression or cluster type of analysis) (to investigate if any particular pattern would emerge on follow-up of the patients).

Mathematical values were assigned to the various groups: dead $=1$, deterioration $=2$, a stable course $=3$, and improvement $=4$.

Throughout the study the null hypothesis was used-that there was no difference between the

* In all cases this method was compared with the width/length method described by Greene et al. ${ }^{16}$ The correlation between the two methods is excellent $(r=0.96, p<0.001)$; the line of regression is coincident with a $45^{\circ}$ slope, but does not pass through the origin (YGreene $=1.05 \times$ S-D -10.46).

Table 1 Information on morphology and haemodynamics

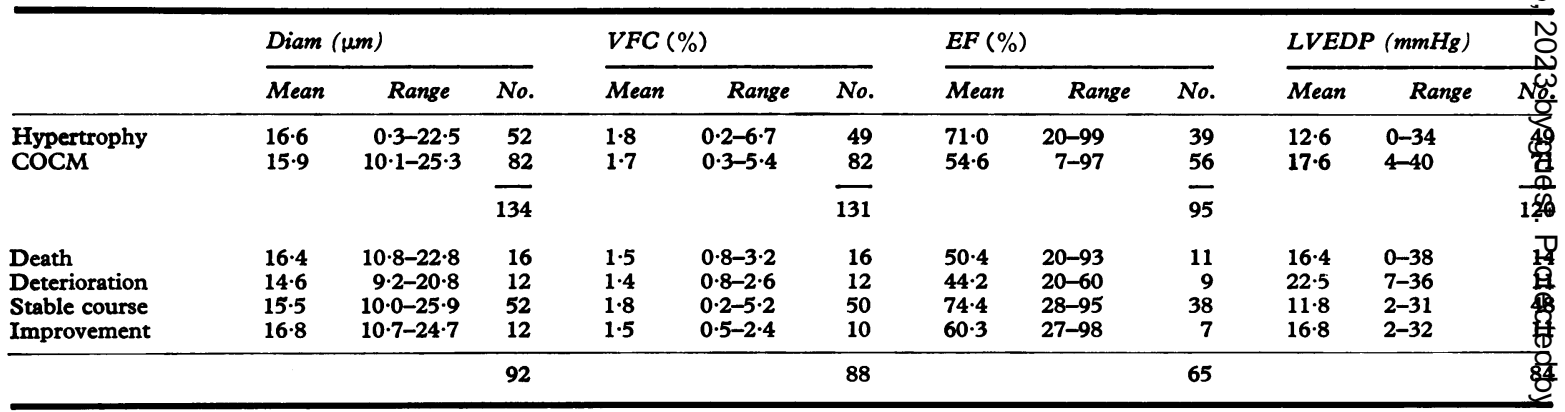

Note: Information on the subsequent course is available in 69 per cent of patients (92/134). In 37 of these 92 patients a histological picture of "ordinary" hypertrophy was found in the biopsies, and in 55 the morphology was compatible with COCM. 
samples or results in question; consequently twotailed tests were appraised. A $p$ value of less than $\mathbf{0 . 0 5}$ was accepted as the limit of significance.

\section{Results}

\section{MORPHOLOGICAL QUANTIFICATION COMPARED WITH CLINICAL/HAEMODYNAMIC INFORMATION}

This is set out in Table 1. Possible differences in subsequent clinical course between the histological groups are set out in Table 2.

Death and deterioration tended to occur more frequently in the group with clinical congestive cardiomyopathy.

One-way analysis of variance of diameter of muscle fibres, volume fraction of collagen tissue, ejection fraction, and left ventricular end-diastolic pressure was undertaken in respect of the subsequent course of the patients in the two histological groups.

The diameter of muscle fibres and the volume fraction of collagen tissue show no statistically significant difference in either group (Table 3) but analysis of the ejection fraction and left ventricular end-diastolic pressure showed some statistically significant differences (Table 4).

Multivariate analysis of these variables was undertaken in order to ascertain if this would predict differences in the subsequent course of the disease but there was no difference in the two histological groups.

Ejection fraction, left ventricular end-diastolic pressure, and length of history were each correlated with the diameter of the muscle fibres, and volume fraction of collagen tissue. The data showed total scatter and no correlations were established. Three graphs from the groups compatible with COCM illustrate these findings (Fig. 1 to 3 ).

\begin{tabular}{|c|c|c|c|c|c|}
\hline \multicolumn{3}{|c|}{ Length (mth) } & \multicolumn{3}{|c|}{ Followv-up (mth) } \\
\hline Mean & Range & No. & Mean & Range & No. \\
\hline $\begin{array}{l}33 \cdot 3 \\
39 \cdot 4\end{array}$ & $\begin{array}{l}1-204 \\
1-240\end{array}$ & $\begin{array}{r}49 \\
76 \\
125\end{array}$ & $\begin{array}{l}28 \cdot 6 \\
18 \cdot 8\end{array}$ & $\begin{array}{l}5-66 \\
2-60\end{array}$ & $\begin{array}{l}40 \\
49 \\
89\end{array}$ \\
\hline $\begin{array}{l}53 \cdot 8 \\
63 \cdot 3 \\
32 \cdot 3 \\
35\end{array}$ & $\begin{array}{l}2-192 \\
1-204 \\
1-204 \\
3-144\end{array}$ & $\begin{array}{l}15 \\
11 \\
49 \\
10\end{array}$ & $\begin{array}{l}12 \cdot 5 \\
29 \cdot 2 \\
22 \cdot 9 \\
30 \cdot 2\end{array}$ & $\begin{array}{r}4-40 \\
12-60 \\
4-60 \\
11-42\end{array}$ & $\begin{array}{l}14 \\
12 \\
47 \\
11\end{array}$ \\
\hline & & 85 & & & 84 \\
\hline
\end{tabular}

Table 2 Patients with "ordinary" hypertrophy and congestive cardiomyopathy analysed according to subsequent course of disease

\begin{tabular}{llll}
\hline Clinical progress & COCM & Hypertrophy & \\
\hline Dead, deterioration & 22 & 6 & 28 \\
Stable improvement & 33 & 31 & 64 \\
& $\frac{55}{37}$ & & 92 \\
\hline
\end{tabular}

$\chi^{2}=4.84, p<0.05$

Table 3 Diameter of muscle fibres (mean, um) and VFC (mean, \%) analysed by one-way analysis of variance

\begin{tabular}{|c|c|c|c|c|}
\hline \multirow[t]{2}{*}{ Clinical progress } & \multicolumn{2}{|c|}{ Hypertrophy } & \multicolumn{2}{|l|}{ COCM } \\
\hline & Diameter & $p$ & Diameter & $p$ \\
\hline $\begin{array}{l}\text { Dead } \\
\text { Deterioration } \\
\text { Stable } \\
\text { Improvement }\end{array}$ & $\begin{array}{l}18 \cdot 4 \\
17 \cdot 1 \\
15 \cdot 6 \\
15 \cdot 7 \\
V F C\end{array}$ & $\int_{p}^{N S}$ & $\begin{array}{l}15 \cdot 8 \\
14 \cdot 6 \\
15 \cdot 5 \\
17 \cdot 5 \\
V F C\end{array}$ & $\int_{p}^{\text {NS }}$ \\
\hline $\begin{array}{l}\text { Dead } \\
\text { Deterioration } \\
\text { Stable } \\
\text { Improvement }\end{array}$ & $\begin{array}{l}1.6 \\
1.2 \\
1.6 \\
1.3\end{array}$ & NS & $\begin{array}{l}1.5 \\
1.8 \\
1.9 \\
1.5\end{array}$ & NS \\
\hline
\end{tabular}

NS: no statistically significant difference.

VFC, volume fraction of collagen tissue.

Table 4 Ejection fraction (EF) (mean, \%) and left ventricular end-diastolic pressure (LVEDP) (mean, $\mathrm{mmHg}$ ) analysed by one-way analysis of variance

\begin{tabular}{|c|c|c|c|c|}
\hline \multirow{2}{*}{ Clinical progress } & \multicolumn{2}{|c|}{ Hypertrophy } & \multicolumn{2}{|l|}{ COCM } \\
\hline & $E F$ & $p$ & $E F$ & $p$ \\
\hline Deterioration & $37 \cdot 3$ & $<0.001$ & $37 \cdot 0$ & NS \\
\hline Improvement & $91 \cdot 7$ & NS & $41 \cdot 4$ & NS \\
\hline Dead & $71 \cdot 2$ & KN & $46 \cdot 1$ & $<0.01<0.001$ \\
\hline Stable & $77 \cdot 6$ & & $67 \cdot 5$ & \\
\hline Deterioration & $\begin{array}{l}\text { LVEDP } \\
25 \cdot 3\end{array}$ & & $\begin{array}{l}\text { LVEDP } \\
23.2\end{array}$ & \\
\hline Improvement & $9 \cdot 8$ & $\left\{\begin{array}{l}<0.001 \\
\text { NS }\end{array}\right.$ & $21 \cdot 4$ & $\begin{array}{l}\text { NS } \\
\text { NS }\end{array}$ \\
\hline Dead & $6 \cdot 2$ & NS & $18 \cdot 0$ & $\int_{<0.001}$ \\
\hline Stable & $11 \cdot 0$ & & $13 \cdot 1$ & \\
\hline
\end{tabular}

Analysis based on clinical diagnosis rather than that based on histological description was undertaken. It was necessary to regroup a few patients, as the two were not always identical. This resulted in two groups, one of 58 patients with COCM and the other with 34 patients who were finally considered not to have this, that is after further 


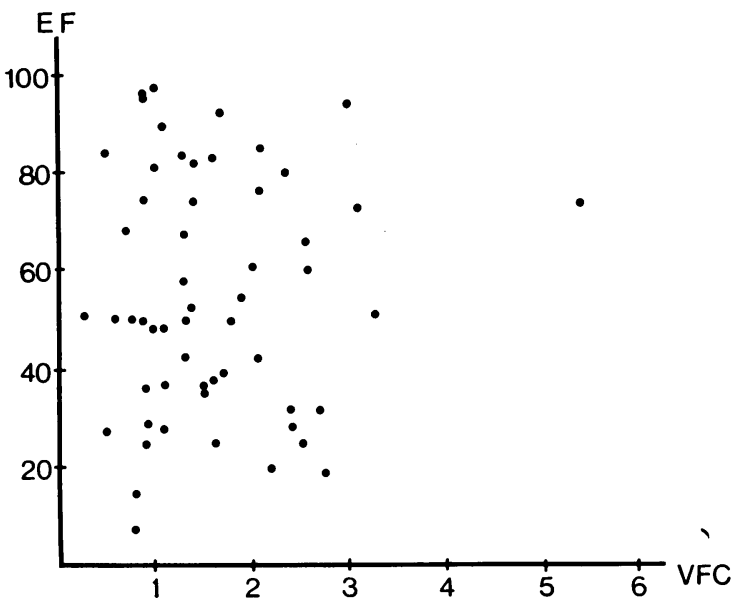

Fig. 1 Plot of ejection fraction (EF) against volume fraction of collagen tissue (VFC) in patients with a histological diagnosis compatible with congestive cardiomyopathy.

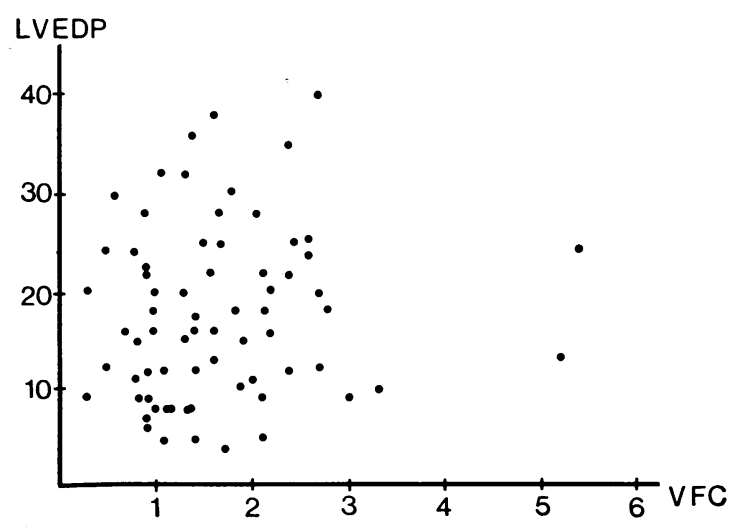

Fig. 2 Plot of left ventricular end-diastolic pressure (LVEDP) against volume fraction of collagen tissue (VFC) in patients with a histological diagnosis compatible with congestive cardiomyopathy.

Table 5 Twenty-six patients with "ordinary" hypertrophy

\begin{tabular}{|c|c|c|c|c|}
\hline & & COCM & CAD/hypert/valv & $p$ \\
\hline Diam ( $\mu \mathrm{m})$ & $\begin{array}{l}\text { Mean } \\
\text { Range }\end{array}$ & $\begin{array}{l}16 \cdot 7 \\
9 \cdot 3-22 \cdot 5\end{array}$ & $\begin{array}{l}18 \cdot 1 \\
13 \cdot 4-21 \cdot 9\end{array}$ & NS \\
\hline VFC (\%) & $\begin{array}{l}\text { Mean } \\
\text { Range }\end{array}$ & $\begin{array}{l}1.5 \\
0.7-3.6\end{array}$ & $\begin{array}{l}1 \cdot 5 \\
0.2-4.1\end{array}$ & NS \\
\hline EF (\%) & $\begin{array}{l}\text { Mean } \\
\text { Range }\end{array}$ & $\begin{array}{l}52 \cdot 9 \\
20-82\end{array}$ & $\begin{array}{l}70 \cdot 1 \\
39-99\end{array}$ & NS \\
\hline $\begin{array}{l}\text { LVEDP } \\
(\mathbf{m m H g})\end{array}$ & $\begin{array}{l}\text { Mean } \\
\text { Range }\end{array}$ & $\begin{array}{l}17 \cdot 2 \\
0-34\end{array}$ & $\begin{array}{c}12 \cdot 3 \\
2-28\end{array}$ & NS \\
\hline
\end{tabular}

CAD, coronary arterial disease; hypert, hypertension; valve, valvar lesion; NS, no statistically significant difference.

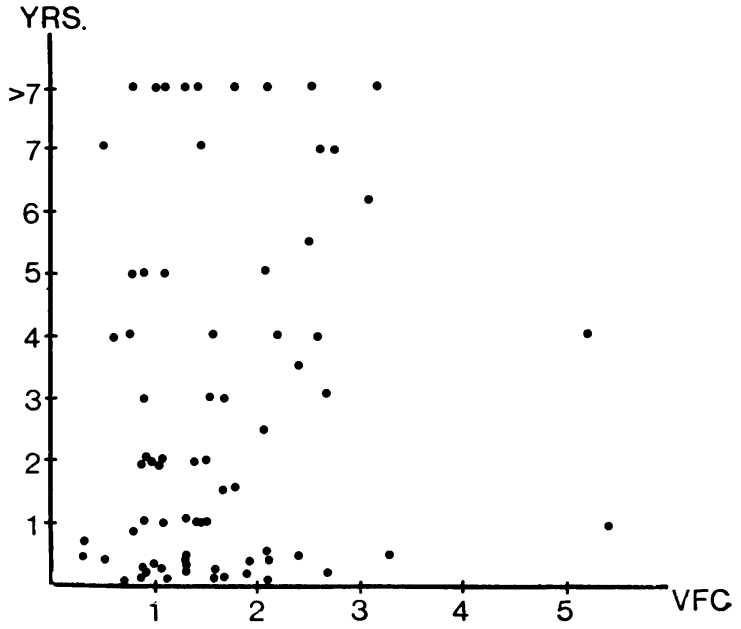

Fig. 3 Plot of "length of history" (yrs) against volume fraction of collagen tissue (VFC) in patients with a histological diagnosis compatible with congestive cardiomyopathy.

investigations and follow-up. Multivariate analysis, however, failed to establish any positive correlation.

Twenty-six patients with "ordinary" hypertrophy were separated according to the final clinical diagnosis; 13 patients with clinical congestive cardiomyopathy and 13 patients who were subsequently found to have coronary heart disease and hypertension and/or valvar lesions, and no cardiomyopathy. There was no statistically significant difference ( $t$ test) between the data in these two groups (Table 5).

\section{COMPARISON OF HISTOLOGICAL DESCRIPTION WITH FINAL CLINICAL \\ DIAGNOSIS}

Provided that the sample is representative, a biopsy from conditions such as hypertrophic cardiomyopathy or myocarditis shows a specific morphology: "histological description" can be replaced by "histological diagnosis". In other conditions no specific changes exist and the histological descriptions compatible with clinical COCM are not pathognomonic for this condition, as similar morphological changes may be seen in a variety of other conditions, such as ischaemic disease or valvar lesions with heart failure. "Ordinary" hypertrophy could apply to an early stage of clinical COCM, the morphological signs of dilatation having not yet developed, or to other conditions.

With these reservations, agreement between histological descriptions and clinical diagnosis was 
present in 86 per cent of cases (Table 6). In four of the remaining patients the clinical diagnosis was not yet firmly established. Five of nine patients in whom a clinical diagnosis of hypertrophic obstructive cardiomyopathy (HOCM) was not histologically confirmed had no obstruction. Of three cases with "Löffler-endomyocardial fibrosis" only one had been histologically verified: in one patient the right ventricular biopsy showed ordinary hypertrophy, but subsequent operation showed endomyocardial fibrosis limited to the left ventricle. In the third patient the diagnosis is suspected on clinical grounds only.

On examination of the clinical notes it was found that the histological report had caused a change of the clinical diagnosis in 15 of 111 patients (Table 7).

In about 10 to 20 per cent of patients with typical anginal chest pain the selective coronary angiograms are normal. ${ }^{18}$ Twenty-nine patients of that category were included in this study (Table 6). The morphological changes in these patients varied; only in two were the biopsies normal.

\section{Discussion}

The haemodynamic variables-ejection fraction and left ventricular end-diastolic pressure-showed a few significant differences when analysed with respect to the subsequent clinical course; but these were ambiguous. Patients with "ordinary" hypertrophy and showing clinical deterioration differed from the rest, and so did patients with COCM and a stable clinical course.

No correlation could be established between morphological quantification, and clinical information (length of history, subsequent course) and haemodynamic variables (ejection fraction, left ventricular end-diastolic pressure) in the two
Table 7 Change of clinical diagnosis in 111 patients

\begin{tabular}{llll}
\hline From & To & $\begin{array}{l}\text { No. of } \\
\text { patients }\end{array}$ & $\begin{array}{l}\text { Opl } \\
\text { necropsy }\end{array}$ \\
\hline COCM & HOCM & 2 & + \\
Aortic stenosis? & HOCM & 1 & + \\
HOCM? & $\begin{array}{l}\text { No HOCM } \\
\text { (hypertension) }\end{array}$ & 1 & \\
COCM & Sarcoidosis & 1 & \\
COCM & No COCM (constrictive & \\
CAD+COCM & pericarditis) & 1 & + \\
COCM & Myocarditis & 1 & \\
NCA & +Myocarditis & 2 & \\
Myocarditis? & Myocarditis & 2 & \\
COCM? rheumatic & No inflammation & 3 & \\
fever & Rheumatic fever & 1 & + \\
\hline & & $15 \sim 13.5 \%$ & \\
& & & \\
\hline
\end{tabular}

CAD, coronary arterial disease; NCA, normal coronary arteries, anginal chest pain.

groups, "ordinary" hypertrophy and COCM. Thus, prognosis or the severity of disease cannot be assessed from histological changes. Davies et al. ${ }^{11}$ agree, but Kunkel et al ${ }^{12}$ do not.

The reasons for this discrepancy could be because of differences in the selection of patients, different definitions of tissue structures; or inadequate endomyocardial biopsies. Quantitative investigations have shown that pronounced topographic variations may be found within the myocardium and only with five or more biopsies is accuracy likely. ${ }^{19}$ With fewer biopsies the changes observed may well be fortuitous and thus a further study on a larger scale using five or more biopsies is needed to settle this point. Such a study might benefit methods of study other than the morphological, for representative sampling is equally important in, for instance, biochemical studies which have been used in the study of heart muscle biopsies.

The myocardium can react only in a limited way

Table 6 Final clinical diagnosis versus histological description

\begin{tabular}{|c|c|c|c|c|c|c|c|c|c|c|c|c|}
\hline & Normal & COCM & HOCM & $\begin{array}{l}\text { Myocard- } \\
\text { itis }\end{array}$ & $\begin{array}{l}\text { LöfflerI } \\
\text { EM }\end{array}$ & $\begin{array}{l}C A D / \\
\text { hypertension }\end{array}$ & $\begin{array}{l}\text { Valvar } \\
\text { lesion }\end{array}$ & Others & $N C A$ & + Lact & $-L a c t$ & \\
\hline \multirow{11}{*}{ 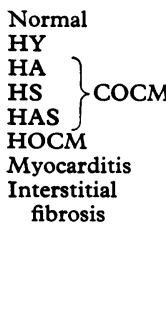 } & 6 & 2 & & & & 1 & & 5 & 1 & & 1 & 16 \\
\hline & 2 & 13 & 6 & & 1 & 8 & 5 & 7 & 5 & 7 & 3 & 57 \\
\hline & & 15 & & & & 5 & 1 & 1 & & 1 & 2 & 25 \\
\hline & & 3 & 1 & & 1 & 3 & & 4 & & & 2 & 15 \\
\hline & & 33 & 1 & & & 2 & 2 & 1 & 1 & 1 & 1 & 42 \\
\hline & & & 8 & & & & & 3 & & & & 11 \\
\hline & & & & 8 & 1 & & & & & & & 9 \\
\hline & & 2 & 1 & & & 1 & & 1 & 2 & 2 & & 9 \\
\hline & 9 & 68 & 17 & 8 & 3 & 20 & 8 & 22 & 9 & 11 & 9 & 184 \\
\hline & & & & & & & & & & & Failed & 17 \\
\hline & & & & & & & & & & & Total & 201 \\
\hline
\end{tabular}

HY, hypertrophy; HA, hypertrophy with attenuation; HS, hypertrophy with smooth muscle cell hypertrophy of the endocardium;

HAS, hypertrophy with attenuation and smooth muscle cell hypertrophy of the endocardium; CAD, coronary arterial disease; NCA, normal coronary arteries, anginal chest pain, no study of lactate production; +Lact, abno mal lactate production in NCA patients;

-Lact, normal lactate production in NCA patients. 
to a variety of stimuli, most commonly with hypertrophy. Morphological descriptions cannot, therefore, always be expressed in terms of clinical diagnoses but the attempt to establish a correlation between morphology and either myocardial function or prognosis with two groups of patients reclassified on clinical grounds as having or as not having COCM was unsuccessful.

In 86 per cent of patients there was a crude correlation between the morphological description and the clinical diagnosis. Similar results-but maybe more optimistically interpreted-have been reported by others.4 2021 A "crude correlation", however, is not adequate.

The biopsies from patients with normal coronary arteries and anginal chest pain showed an abnormal morphology. Though the histological changes were not uniform, this finding strongly supports the view that these patients are suffering from a myocardial disorder. ${ }^{78}$ No evidence of small vessel disease was found, a confirmation of the findings by Richardson et al. ${ }^{22}$

In 13.5 per cent of patients morphological and morphometric examination altered the clinical diagnosis and thus treatment and prognosis. This alone in our opinion justifies the continued use of myocardial biopsy of these patients.

To establish the value of histological examination of endomyocardial tissue the diagnostic sensitivity and specificity of the procedure should be known but this will need a prospective study in which the morphological descriptions are first defined precisely, and are related to specific clinical diagnoses.

We are grateful to Dr C M Oakley, London, Dr A Torp, Malmö, and Professor H D Bolte, München, for supplying some of the biopsies.

This study has been supported by grants from the Danish Heart Foundation, Marie de Lancy Petersen's Fund, and the Anglo-Danish Society.

This work formed part of the thesis by U B for the degree of Doctor of Philosophy ( $\mathrm{PhD}$ ) for the University of London.

\section{References}

1 Sakakibara S, Konno S. Endomyocardial biopsy. fpn Heart $\mathcal{F}$ 1962; 3: 537-43.

2 Konno S, Sakakibara S. Endomyocardial biopsy. Dis Chest 1963; 44: 345-50.

3 Somers K, Hutt MSR, Patel AK, D'Arbela PG. Endomyocardial biopsy in diagnosis of cardiomyopathies. Br Heart $\mathcal{F}$ 1971; 33: 822-32.

4 Olsen EGJ. Diagnostic value of the endomyocardial biopsy. Lancet 1974; i: 658-60.
5 MacKay EH, Littler WA, Sleight P. Critical assessment of diagnostic value of endomyocardial biopsy. Assessment of cardiac biopsy. Br Heart $\mathcal{F} 1978$; 40: 69-78.

6 Peters TJ, Wells G, Brooksby IAB, Jenkins BS, Webb-Peploe MM, Coltart DJ. Enzymic analysis of cardiac biopsy material from patients with valvular heart-disease. Lancet 1976; i: 269-70.

7 Peters TJ, Wells G, Oakley CM, et al. Enzymic analysis of endomyocardial biopsy specimens from patients with cardiomyopathies. Br Heart $\mathcal{f}$ 1977; 39: 1333-9.

8 Richardson PJ, Atkinson L, Oram S. Enzyme activities in endomyocardial biopsy samples from patients with cardiomyopathy (abstract). Br Heart $\mathcal{f}$ 1978; 40: 456.

9 Bolte HD. Immunologic investigation in patients with cardiomyopathies. In: Kaltenbach $M$, Loogen F, Olsen EGJ, eds. Cardiomyopathy and myocardial biopsy. Berlin, Heidelberg, \& New York: SpringerVerlag, 1978: 251-5.

10 Hatle L, Melbye OJ. Immunoglobulins and complement in chronic myocardial disease. Acta Med Scand 1976; 200: 385-9.

11 Davies MJ, Brooksby IAB, Jenkins BS, et al. Left ventricular endomyocardial biopsy II: the value of light microscopy. Cathet Cardiovasc Diagn 1977; 3: 123-30.

12 Kunkel B, Lapp H, Kober G, Kaltenbach M. Correlations between clinical and morphologic findings and natural history in congestive cardiomyopathy. In: Kaltenbach M, Loogen F, Olsen EGJ, eds. Cardiomyopathy and myocardial biopsy. Berlin, Heidelberg, \& New York: Springer-Verlag, 1978: 271-83.

13 Seldinger SI. Catheter replacement of the needle in percutaneous arteriography: a new technique. Acta Radiol 1953; 39: 368-76.

14 Gau GT, Goodwin JF, Oakley CM, et al. Q waves and coronary arteriography in cardiomyopathy. $\mathrm{Br}$ Heart f 1972; 34: 1034-41.

15 Sandler H, Dodge HT. The use of single plane angiocardiograms for the calculation of left ventricular volume in man. Am Heart $\mathcal{f} 1968$; 75: 325-34.

16 Greene DG, Carlisle R, Grant C, Bunnell IL. Estimation of left ventricular volume by one-plane cineangiography. Circulation 1967; 35: 61-9.

17 Goodwin JF. Myocardial diseases. Medicine 2nd series 1975-7; 25: 1286-96.

18 Richardson PJ, Atkinson L, Jackson G. Myocardial ischaemia and its relationship to coronary arterial disease. Investigation of angina pectoris with normal coronary arteries. In: Carlson LA, Paoletti A, Sirtoria CA, Weber G, eds. International conference on atherosclerosis. New York: Raven Press, 1978: 71-4.

19 Baandrup U. Endomyocardial biopsy in suspected cardiomyopathy - a morphological and morphometric analysis. Thesis, University of London, 1979.

20 Sekiguchi M, Konno S. Diagnosis and classification of primary myocardial disease with the aid of endomyocardial biopsy. $\mathcal{F p n} \operatorname{Circ} \mathcal{F} 1971$; 35: 737-54. 
21 Billingham ME. Some recent advances in cardiac pathology. Hum Pathol 1979; 10: 367-86.

22 Richardson PJ, Livesley B, Oram S, Olsen EGJ, Armstrong $P$. Angina pectoris with normal coronary arteries. Transvenous myocardial biopsy in diagnosis.
Lancet 1974; ii: 677-80.

Requests for reprints to Dr E G J Olsen, Department of Histopathology, National Heart Hospital, Westmoreland Street, London W1M 8BA. 